\title{
Testosterone modulates mitochondrial aconitase in the full-length human androgen receptor-transfected PC-3 prostatic carcinoma cells
}

\author{
H-H Juang, M-L Hsieh ${ }^{1}$ and K-H Tsui ${ }^{1}$ \\ Department of Anatomy, Chang Gung University, 259 Wen-Hua 1st Road, Kwei-Shan, Tao-Yuan 333, Taiwan, Republic of China \\ ${ }^{1}$ Department of Urology, Chang Gung Memorial Hospital, Kwei-Shan, Tao-Yuan 333, Taiwan, Republic of China \\ (Requests for offprints should be addressed to H-H Juang; Email: hhj143@mail.cgu.edu.tw)
}

\begin{abstract}
In vitro studies indicated that dihydrotestosterone (DHT) stimulates the enzymatic activity of the mitochondrial aconitase (mACON) in androgen-sensitive prostatic carcinoma cells, LNCaP. Cell proliferation assay determined that DHT doubles the optimal proliferation response of LNCaP cells. The androgen-insensitive human prostatic carcinoma cells, PC-3, were overexpressed in the human androgen receptor to assess the involvement of the native androgen receptor in the regulation by DHT of mACON gene expression. A stable-transfected clone that expresses the full-length androgen receptor was selected and termed PCAR9. The results revealed that DHT-treated PCAR9 cells paradoxically not only reduced the enzymatic activity of mACON but also blocked the biosynthesis of intracellular ATP attenuating cell proliferation. Transient gene expression assay indicated that $\mathrm{DHT}$ divergently regulates the promoter activity of the mACON gene in LNCaP and PCAR9 cells. This study suggested that DHT regulates $\mathrm{mACON}$ gene expression and the proliferation of cells in a receptor-dependent model through modulation by unidentified non-receptor factors.
\end{abstract}

Journal of Molecular Endocrinology (2004) 33, 121-132

\section{Introduction}

The differentiation, development and maintenance of the prostate gland are under the direct control of androgen (Cunha et al. 1987). The epithelial compartment of the prostate gland in humans and other animals has the unique function of accumulating and secreting extremely high levels of citrate (Franklin et al. 1986). The net citrate secretion rate is determined by the rates of citrate synthesis and citrate oxidation; testosterone controls the balancing mechanism in the rat ventral prostate (Costello \& Franklin 1991). Evidence is emerging that the enzymatic activity of many enzymes involved in metabolizing citrate in the prostate also depends on dihydrotestosterone (DHT) (Costello \& Franklin 2002). Mutation of the androgen receptor is not a major mechanism in the process of prostate cells that become androgen growth independent (Taplin et al. 1995). It is well known that DHT has a positive effect on the proliferation of androgen- sensitive prostatic carcinoma (LNCaP) cells; however, early study has indicated that DHT treatment inhibits the proliferation of LNCaP cells which were long-term cultured in a medium without steroids (Liao et al. 1995). Other studies have also shown that DHT suppresses malignancy and triggers the cell cycle arrest of the androgen receptor-transfected bone metastatic prostate cells, PC-3 (Yuan et al. 1993, Heisler et al. 1997). Hence, the function of androgen and androgen receptor in the prostate has been suspected to vary with the state of malignancy.

Aconitase (aconitase hydratase, EC4 $\cdot 2 \cdot 1 \cdot 3$ ) containing a $[4 \mathrm{Fe}-4 \mathrm{~S}]$ cluster is regarded as the key enzyme responsible for the interconversion of citrate and isocitrate in the citric acid cycle (Emptage et al. 1983). Citrate oxidation via the Krebs cycle is the major pathway for energy production from carbohydrate and fat metabolism. From previous reports, the citrate that is synthesized by prostate cells is accumulated and secreted 
rather than oxidized. The limiting mitochondrial aconitase $(\mathrm{mACON})$ activity prevents citrate from entering the Krebs cycle that induces accumulation and secretion of citrate from the prostate epithelial cells (Costello \& Franklin, 1991). A bioenergetic hypothesis of prostate malignancy suggests that a normal citrate-producing prostatic epithelial cell becomes a citrate-oxidizing cell following a transformation in which mACON is not limiting (Costello \& Franklin 1994). Our previous in vitro study demonstrated that mACON-antisense stabletransfected PC-3 cells have lower citrate utility, intracellular ATP biosynthesis and cell proliferation than the mock-transfected cells (Juang, 2004a). Although early studies have demonstrated that androgen treatment promotes citrate oxidation and citrate secretion in $\mathrm{LNCaP}$ cells, in transient rat androgen receptor-transfected PC-3 cells, in the rat ventral prostate and in the pig prostate (Costello et al. 1995, 1996, Franklin et al. 1995, Juang et al. 1995), the regulation of mACON in the human prostate is not well understood.

\section{Materials and methods}

\section{Cell culture and chemicals}

PC-3 and LNCaP cell lines were obtained from the American Type Culture Collection. LNCaP cells are the unique tumor cell line derived from the supraclavicular lymph node metastasis from the human prostatic carcinoma which exhibits increased proliferation in response to androgens in vitro (Horoszeqicz et al. 1983). The PG-3 cell line was isolated from the bone metastasis of a 62 -year-old patient with stage IV prostatic cancer

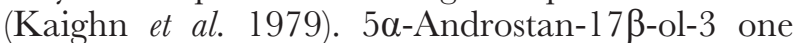
(DHT) and charcoal (dextran-coated) were purchased from Sigma and the BCA protein concentration assay kit was purchased from Pierce (Rockford, IL, USA). Fetal calf serum (FCS) was purchased from HyClone (Logan, UT, USA) and RPMI 1640 medium and RPMI 1640 phenol red-free (RPMI-PRF) medium were purchased from Life Technologies). The FCS, which was treated with charcoal $(1 \mathrm{~g} / 500 \mathrm{ml} \mathrm{FCS})$ for $24 \mathrm{~h}$ to remove the steroids, was considered to be the charcoal-dextran-treated FGS (CD-FCS) in this study. PC-3 and LNCaP cells were maintained in an RPMI 1640 medium that contained 10\% FCS and the medium was changed twice a week.

\section{Construction of the androgen receptor overexpression vector}

The full-length human androgen receptor cDNA clone was kindly provided by Dr S Liao (Chang et al. 1988). Two fragments of human androgen receptor cDNA were digested: one was digested with EcoRI and HindIII, and the other was digested with HindIII and XbaI resulting in $2 \cdot 3$ and $1.3 \mathrm{~kb}$ fragments respectively. The overexpression vector, pcDNA3 (Invitrogen), was digested with EcoRI and XbaI, and the linearized plasmid DNA was ligated with the $2 \cdot 3 \mathrm{~kb}$ EcoRI-HindIII and the $1.3 \mathrm{~kb}$ HindIII-XbaI human androgen cDNA fragments, resulting in the insertion of the full-length androgen receptor cDNA in the polyadenlyate region that was controlled by the human cytomegalovirus immediate-early (GMV) promoter (pcDNA3AR). Proper ligation was confirmed by extensive restriction mapping and sequencing.

\section{Stable transfection of androgen receptor into PC-3 cells}

PG-3 cells were transfected with pcDNA3AR overexpression vector using lipofectin as described by the manufacturer (Life Technologies). Briefly, the transfected cells were incubated for $48 \mathrm{~h}$ in RPMI 1640 supplemented with 10\% fetal bovine serum (FBS). Then, the cells were incubated for 2 weeks in the same medium supplemented with Geniticin (G418; PAA laboratories, Linz, Austria) to a final concentration of $800 \mu \mathrm{g} / \mathrm{ml}$. The resulting Geniticin-resistant cells were plated in a 96-well plate with a limiting dilution. One selected single, resistant colony was then examined to evaluate the expression of the androgen receptor using immunoblotting assay and cell immunocytochemical staining. One clone that expressed the highest concentration of the full-length androgen receptor $(110 \mathrm{kDa})$ in the nuclei was selected and termed the PGAR9. The mock-transfected PG-3 cells (PCDNA) were transfected with controlled pcDNA3 expression vector that lacked the androgen receptor $\mathrm{cDNA}$ insert. The PCDNA cells were clonally selected in the same way as the PCAR9 cells.

\section{Immunocytochemical staining of cells}

LNCaP, PGAR9 and PCDNA cells were grown on the surface of the cover slides for $48 \mathrm{~h}$. Cells were 
Table 1 Primers required by RT-PCR to synthesize the human androgen receptor (AR) and $\beta$-actin cDNAs

\section{Sequence}

Primer

AR1sense

AR1antisense

AR2sense

AR2antisense

AR3sense

AR3antisense

$\beta$-Actin-sense

$\beta$-Actin-antisense
5'-CCAAGACCTACCGAGGAGCT-3'
5'-GCTGTGAAGGTTGCTGTTCC-3'
5'-CGGACGAGGATGACTCAG-3'
5'-TCTTCAGTGCTCTTGCCTGC-3'
5'-CTGGCTTCCGCAACTTACAC-3'
5-'TGGTAGAAGCGTCTTGAGCA-3'
5'-GAAGATCAAGATCATTGCTCCTCC-3'
5'-CTGGTCTCAAGTCAGTGTACAGG-3'

\section{Location}

+47 to +66

+355 to +336

+458 to +475

+914 to +895

+2172 to +2191

+2576 to +2577

+975 to +998

+1698 to +1676 washed with PBS and then fixed with cold acetone for $15 \mathrm{~min}$. Cells were immunocytochemically stained using a VECTASTAIN ABG kit according to the manufacturer's instructions (Vector; Burlingame, CA, USA). Cells were detected using 1:500 of anti-bovine mitochondrial aconitase antiserum (kindly donated by Dr R B Franklin) and rabbit anti-human androgen receptor $\mathrm{N}$-terminal (N-20) and C-terminal (C-19) polyclonal antibodies (Santa Cruz Biotechnology, Santa Cruz, CA, USA).

\section{Reverse transcription (RT)-PCR}

Total RNA was isolated using Trizol reagent and the cDNA was synthesized using the superscript III preamplification kit according to the manufacturer's instructions (Life Technologies). Templateprimer annealing was conducted at $50{ }^{\circ} \mathrm{C}$ for $2 \mathrm{~h}$. Excess RNA was degraded by RNase $\mathrm{H}$ treatment. Table 1 shows the primers used for synthesis of the human androgen receptor cDNA in RT-PCR. The PGR reaction was carried out in a thermal cycler (Thermolyne, IA, USA), for 35 cycles at $94{ }^{\circ} \mathrm{C}$ for $1 \mathrm{~min}, 55^{\circ} \mathrm{C}$ for $1 \mathrm{~min}$ and $72{ }^{\circ} \mathrm{C}$ for $1 \mathrm{~min}$. The PCR products were separated by $2 \%$ agarose gel electrophoresis and visualized using ethidium bromide staining.

\section{Chloramphenicol acetyltransferase (CAT) assay}

PCAR9 and PCDNA cells were transiently transfected with pMSG-CAT (Amersham) using lipofectin as described above. pMSG-CAT contains the mouse mammary tumor virus (MMTV) promoter as a mammalian positive control vector for the glucocorticoid inducible expression of CAT. After the transfected cells were grown for $12 \mathrm{~h}$ in RPMI-PRF medium without FCS, the cells were cultured in the same medium with $2 \%$ CD-FCS, with or without $10 \mathrm{nM}$ DHT, for an additional $48 \mathrm{~h}$. Cells were harvested and resuspended in $100 \mu \mathrm{l} 0 \cdot 25 \mathrm{M}$ Tris buffer $(\mathrm{pH} 7 \cdot 5$ ) for CAT assay as described elsewhere (Juang et al. 1995).

\section{Mitochondrial aconitase activity assay}

Cells were suspended in $100 \mu \mathrm{l} 0 \cdot 25 \mathrm{M}$ sucrose buffered with $50 \mathrm{mM}$ HEPES and 0.007\% digitonin on ice for $5 \mathrm{~min}$. After centrifugation the pelleted mitochondrial material was resuspended in $100 \mu \mathrm{l} \mathrm{HDGG}$ (20 mM HEPES (pH 7.5), $1 \mathrm{mM}$ dithiothreitol (DTT), 10\% glycerol, $2 \mathrm{mM}$ trisodium citrate, $0.5 \mathrm{mg} / 1$ leupeptin, $0.7 \mathrm{mg} / \mathrm{l}$ pepstatin and $0.2 \mathrm{mM}$ phenylmethylsulfonyl fluoride (PMSF)). The membrane of the mitochondrial particle was broken apart in the presence of $1 \%$ Triton X-100. Reaction was carried out in

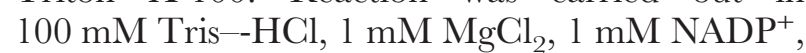
$1 \mathrm{U}$ isocitrate dehydrogenase $(\mathrm{ICDH})$ and $1 \mathrm{mM}$ citrate (Drapier \& Hibbs 1996). The mACON enzymatic activities of the cells were adjusted according to the concentration of protein in the mitochondrial extract, which was measured using the BCA protein assay kit.

\section{Cell proliferation assay}

The cellular proliferation of LNCaP, PCAR9 and PCDNA cells in response to DHT was measured by the conversion of an MTS tetrazolium salt 
(3-(4,5-dimethylthiazol-2-yl)-5 (3-carboxymethoxyphenyl)-2-(4-sulphopheny)-2H-tetrazoluim, inner salt) into a formazan product by viable cells and absorbance at $490 \mathrm{~nm}$ using the cell Titer96QA $\mathrm{Q}_{\text {ueous }}$ cell proliferation assay (Promega). In this assay 5000 cells were cultured to each well of a 96-well plate in RPMI 1640 medium with $10 \%$ FCS for $48 \mathrm{~h}$, and in RPMI-PRF medium with 2\% CD-FCS for $24 \mathrm{~h}$ thereafter. The cells were then incubated with $100 \mu \mathrm{l}$ of $0,0 \cdot 1,1,10$ and $100 \mathrm{nM}$ DHT in the same medium for an additional $72 \mathrm{~h}$. MTS dye solution was added and the plates were read $3 \mathrm{~h}$ later. The number of cells in each well was counted using an enzyme-linked immunosorbent assay (ELISA) microplate reader (Dynex Technologies, Chantilly, VA, USA). The medium and DHT treatments were changed daily.

\section{Immunoblot assay of androgen receptor, mitochondrial aconitases and $\beta$-actin}

Cells $\left(1 \times 10^{6}\right.$ cells/flask $)$ at $80-90 \%$ confluence were incubated with RPMI-PRF medium with $2 \%$ CD-FGS and various concentrations of DHT. Cells were lysed with lysing buffer $(62.5 \mathrm{mM}$ Tris (pH 6.8), 2\% SDS, 10\% glycerol, 5\% $\beta$-mercaptoethanol, $7 \mathrm{M}$ urea, $5 \mu \mathrm{g} / \mathrm{ml}$ leupeptin, $1 \mathrm{mM}$ PMSF). The concentrations of protein in the aliquot samples were measured using the BCA protein assay kit. Equal amounts of protein (60 $\mu \mathrm{g} /$ lane) were analyzed by the ECL detection system, as described by the manufacturer (Amersham). The proteins were probed with 1:500 anti-bovine mitochondrial aconitase antiserum, 1:500 diluted rabbit anti-human androgen receptor N-terminal (N-20) and C-terminal (C-19) polyclonal antibodies or $1: 1000$ diluted anti $\beta$-actin antiserum (C11; Santa Cruz Biotechnology).

\section{Citrate secretion and intracellular ATP assay}

Cells $\left(1 \times 10^{5}\right.$ cells/well $)$ were seeded into each well of a six-well plate. After being treated for $48 \mathrm{~h}$ with DHT at various concentrations, the media were collected, vacuum-dried, resuspended in $300 \mu \mathrm{l}$ water, and deproteinized by adding $300 \mu \mathrm{l}$ $70 \%$ (w/w) perchloric acid. The mixture was centrifuged at $1000 \boldsymbol{g}$ for $15 \mathrm{~min}$ to remove the protein. The supernatant was mixed with $200 \mu \mathrm{l}$ $0.75 \mathrm{M} \mathrm{K}_{2} \mathrm{CO}_{3}$ on ice for an additional $15 \mathrm{~min}$. The precipitate and supernatant were separated by further centrifugation at $1000 \boldsymbol{g}$ for $15 \mathrm{~min}$. The citrate concentrations in the supernatants were determined by tracking $\mathrm{NADH}$ oxidation from the coupled reactions (Möllering \& Gruber 1966). The reaction system contained $1 \mathrm{ml}$ glycylglycine buffer $(0.5 \mathrm{M}) / \mathrm{ZnCl}_{2}(0.6 \mathrm{mM})(\mathrm{pH} 7 \cdot 8), 20 \mu \mathrm{l}$ malate dehydrogenase $(\mathrm{MDH} ; 600 \mathrm{U} / \mathrm{ml}) / \mathrm{L}$-lactate dehydrogenase (LDH; $1375 \mathrm{U} / \mathrm{ml}), 100 \mu \mathrm{l} \mathrm{NADH}$ $(10 \mathrm{mM})$ and $500 \mu \mathrm{l}$ sample. The reaction was initiated by adding $20 \mu \mathrm{l}$ citrate lyase $(40 \mathrm{U} / \mathrm{ml})$. Cells were collected by centrifugation at $300 \boldsymbol{g}$ for 10 min. The concentrations of intracellular ATP were determined using an ATP assay kit, as described by the manufacturer (CalBiochem, San Diego, CA, USA). The $100 \mu \mathrm{l}$ of cell extract in the HEPES buffer (25 mM; pH 7.75) was mixed with the ATP-releasing reagent and the reaction was initiated by injecting firefly luciferin-luciferase solution. The peak height of light emission was measured using a LumiCount (Packard Bioscience, Meriden, GT, USA). The ATP concentrations were determined directly from the standard curve. The concentration of citrate in the medium and the intracellular ATP were adjusted according to the concentrations of proteins of the whole-cell extract, as determined using the BCA protein assay kit.

\section{Luciferase and $\beta$-galactosidase assay}

LNCaP or PCAR9 cells were plated onto 24-well plates at $1 \times 10^{4}$ cells/well 1 day prior to transfection. The cells were transiently transfected using TransFast transfection reagent $(0 \cdot 6 \mu \mathrm{g} /$ well; Promega), $1 \mu \mathrm{g}$ /well reporter vector and $0.5 \mu \mathrm{g}$ / well $\beta$-galactosidase ( $\beta$-GAL) expression vector (pCMVSPORT $\beta g a l)$ in the serum reduction medium (OPTI-medium; Life Technologies) for $4 \mathrm{~h}$. The cells continued to be incubated in RPMI 1640 medium with 10\% FCS overnight. Before they were treated with DHT, the cells were washed and incubated in the RPMI-PRF medium with $2 \%$ CD-FCS for $6 \mathrm{~h}$. After treatment with DHT for an additional $48 \mathrm{~h}$ in the same medium, the reactants were washed twice in PBS and the reaction terminated by adding $200 \mu \mathrm{l}$ of luciferase cell culture lysis reagent (Promega). Twenty microliters of cell lysate were used for luciferase assay using luciferase assay kit, and $100 \mu \mathrm{l}$ cell lysate was used for the $\beta$-GAL enzyme assay as described by the manufacturer (Promega). The luciferase activity was determined in relative light units (RLUs) using 
LumiCount (Packard BioScience) and adjusted according to the $\beta$-GAL enzymatic activity.

\section{Statistical analysis}

Results are expressed as the means \pm s.E. obtained from at least three independent replications of each experiment. Statistical significance was determined by paired $t$-test analysis using the SigmaStat program for Windows version 2.03 (SPSS Inc, Chicago, IL, USA).

\section{Results}

In vitro studies indicated that DHT $(10 \mathrm{nM})$ markedly stimulates not only the enzymatic activity but also the protein level of $\mathrm{mACON}$ in the androgen-sensitive prostatic carcinoma cell, LNCaP (Fig. 1A and G). The MTS assays revealed that DHT doubles the optimal proliferation response of LNCaP cells (Fig. 1B). The increase in $\mathrm{mACON}$ activity was associated with an increase in the intracellular biosynthesis of ATP in the LNCaP cells after DHT treatments (Fig. 2A). However, the citrate concentration in the medium also increased after LNCaP cells were treated with the DHT (Fig. 2B).

The human androgen cDNA was stably transfected to an androgen-insensitive human prostate carcinoma cell line, PC-3, to evaluate the function of the native androgen receptor in the effect of the DHT on mACON gene expression and cell proliferation. The clonally selected PC-3 cells transfected with androgen receptor overexpression vector (pcDNA3AR) or mock-overexpression vector (pcDNA3) were maintained in the RPMI 1640 medium with $10 \%$ FCS and $800 \mu \mathrm{g} / \mathrm{ml} \mathrm{G} 418$. The concentrations of androgen receptor in the selected clones were determined by immunoblotting assay. The clone, PCAR9, that expressed the highest concentration of full-length androgen receptor, was chosen. Cell immunocytochemical staining revealed that PCAR9 cells expressed androgen receptors that were fixed in the nuclei in the same way as LNCaP cells. However, when LNCaP, PGDNA and PGAR9 cells were immunostained with $\mathrm{mACON}$ antibody, the results showed that the mACON of those cells was specifically expressed in the cytoplasm (Fig. 3). Immunoblotting assay, using $\mathrm{N}$-terminal (Fig. 4A) or C-terminal rabbit anti- human androgen receptor polyclonal antibodies, revealed an immunoreactive protein with an apparent molecular weight of $110 \mathrm{kDa}$ in PCAR9 cells, as in LNCaP cells; however, this immunoreactive androgen receptor is absent from mocktransfected PG-3 cells, PCDNA (Fig. 4B). Results from RT-PCR also verified that both PCAR9 cells and LNCaP cells expressed the full-size androgen receptor mRNA (Fig. 4C).

PCAR9 and PCDNA cells were transiently transfected with the positive control vector that contained the androgen-sensitive MMTV promoter fused to a CAT reporter gene. The results of treating cells with $10 \mathrm{nM}$ DHT for $48 \mathrm{~h}$ showed that DHT treatment doubled CAT activity in PCAR9 cells; however, DHT treatment did not affect the CAT activity in PCDNA cells (Fig. 5). The PGAR9 cells seemed to express functional AR protein that was transcriptionally active in an amount that sufficed to induce the transcription of the CAT gene. This stable transfectant, which continues to respond to androgen in vitro, provides an accurate tool for studying wild-type human androgen receptor activation and its regulation by androgen.

The regulation by DHT treatments of the proliferation of PCAR9 and PCDNA cells was examined. The results from MTS assays indicated that DHT treatments do not considerably affect the relative proliferation of PGDNA cells. On the contrary, the considerable inhibition by DHT treatment of the growth of PCAR9 cells, unlike that of LNCaP cells, was dose dependent (Fig. 6A).

Considerably more endogenous mitochondrial aconitase is present in PCDNA cells $(0 \cdot 81 \pm 0 \cdot 01$ $\mathrm{U} / \mu \mathrm{g}$ mitochondria) than in PCAR9 cells $(0 \cdot 62 \pm$ $0.01 \mathrm{U} / \mu \mathrm{g}$ mitochondria) [q;6 units in Fig. $6 \mathrm{~B}$ are 'U/mg mitochondria' (i.e. not $\boldsymbol{\mu g}$ as in text); which is correct; please check units on all Figures]. The results showed that DHT treatments did not affect the enzymatic activity of mACON in PCDNA cells; however, DHT treatment $(10 \mathrm{nM})$ inhibited enzymatic activity of mACON by $50 \%$ in PGAR9 cells (Fig. 6B). Moreover, the intracellular ATP level of PCAR9 cells dropped $60 \%$ after $10 \mathrm{nM}$ DHT treatment (Fig. 6C). Although the DHT treatment inhibits the enzymatic activity of mACON in PCAR9 cells, the rate of citrate secretion from PCAR9 cells was also markedly reduced by $40 \%$ after $10 \mathrm{nM}$ DHT treatment (Fig. 6D). Immunoblot assay indicated that DHT significantly 
down-regulates the protein levels of mACON in PCAR9 cells (Fig. 7A). The results suggested that DHT regulates the enzymatic activity of mACON in PCAR9 cells at the transcriptional level.

The human mACON gene, containing 18 exons (GenBank accession no. HSACO2 G01HSACO2 G17), was cloned and sequenced in our laboratory (Juang 2004b). An EcoRI-digested $9 \mathrm{~kb}$ DNA fragment was cloned and identified as the 5 '-flanking region of the mACON gene. Two DNA fragments were cloned into the pbGL3 reporter

(A)

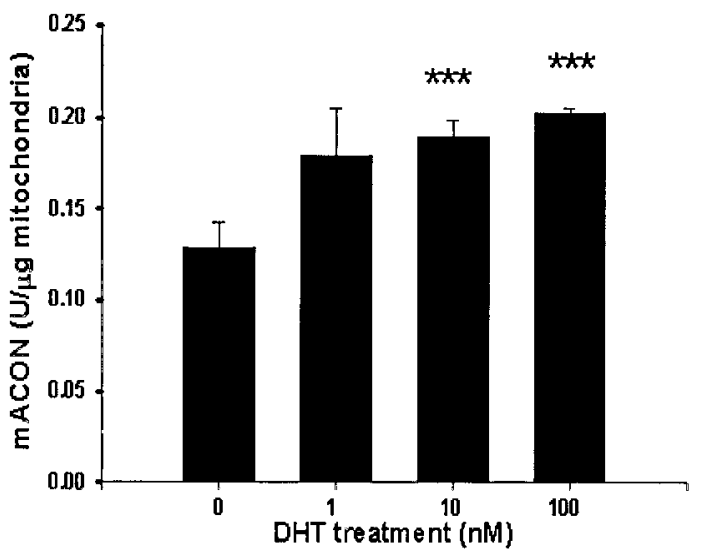

(B)

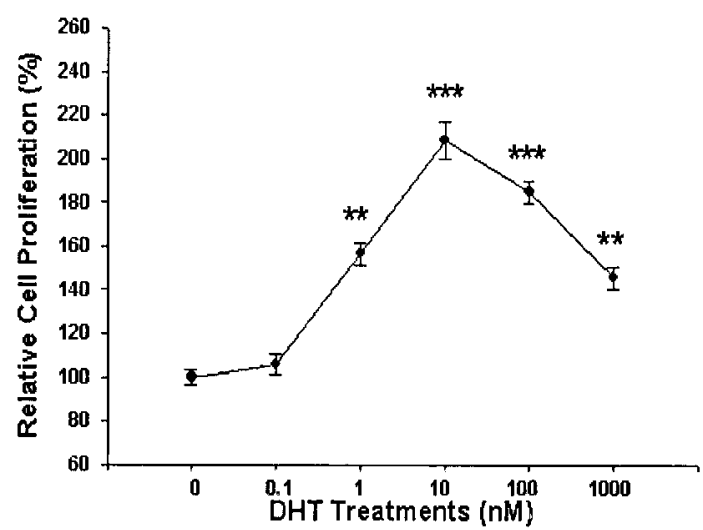

(C)

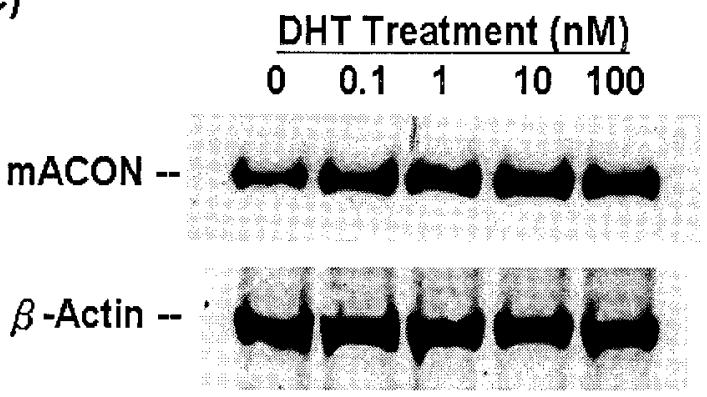

vector (Progema) designed as pbGL743 ( -1013 to +38 ) and pbGL188 ( -158 to +38$)$. Transient gene expression assays indicated that the putative promoter was located at the DNA fragment $(-158$ to +38 ) of the $5^{\prime}$-flanking region of the human mACON gene (Fig. 7B). Although DHT treatment $(10 \mathrm{nM})$ doubled the activity of the reporter activity when the pbGL188 vectors were transiently transfected into the LNGaP and PGAR9 cells, DHT treatment $(10 \mathrm{nM})$ was found to enhance the promoter activity of the mACON gene when pbGL743 vectors were transiently transfected into LNCaP cells. In contrast, the same treatment inhibits the promoter activity in pbGL743transfected PGAR9 cells (Fig. 7C and D). DHT was found to operate by a divergent regulative mechanism on the mACON gene in LNCaP and PGAR9 cells. These results implied that the regulation by DHT of the transcription of the mACON gene in LNCaP or PGAR9 cells may depend on the receptor and the modulation of unknown non-receptor factors.

\section{Discussion}

The growth of the normal prostate is well known to depend largely on androgens and DHT, which are very important in the prostatic pathophysiology (Lopez-Otin \& Diamandis 1998). Early in vivo studies found that testosterone tissue specifically induces the biosynthesis of mACON and its

Figure 1 Modulation by DHT of enzymatic activity and gene expression of $\mathrm{mACON}$ and the proliferation of LNCaP cells. (A) LNCaP cells were treated with different concentrations of DHT, as indicated, in an RPMI-PRF medium with $2 \% \mathrm{CD}-\mathrm{FCS}$ for $24 \mathrm{~h}$. The enzymatic activities of mACON were determined as described in Materials and methods. Experimental data are presented as means \pm S.E. $(n=5)$ of the enzymatic activity induced by DHT treatments $\left({ }^{* *} P<0 \cdot 001\right)$. (B) LNCaP cells $(5000$ cells/well) were treated with DHT $(0.1-100 \mathrm{nM})$ in $100 \mu \mathrm{l}$ RPMI-PRF medium with $2 \%$ CD-FCS for $72 \mathrm{~h}$. The number of cells were counted using an MTS assay kit. Each point of the curve represents the mean-percentage stimulations of $490 \mathrm{~nm}$ absorbance induced by DHT treatments relative to that of a sample that had been mock-treated $\left({ }^{\star \star} P<0.05\right.$; ${ }^{* \star \star} P<0.001$ ). (C) LNCaP cells were treated with different concentrations of DHT, as indicated, in the RPMI-PRF medium with 2\% CD-FCS for $24 \mathrm{~h}$. Cells were harvested and lysed to extract protein for use in the immunoblot assay. 
(A)

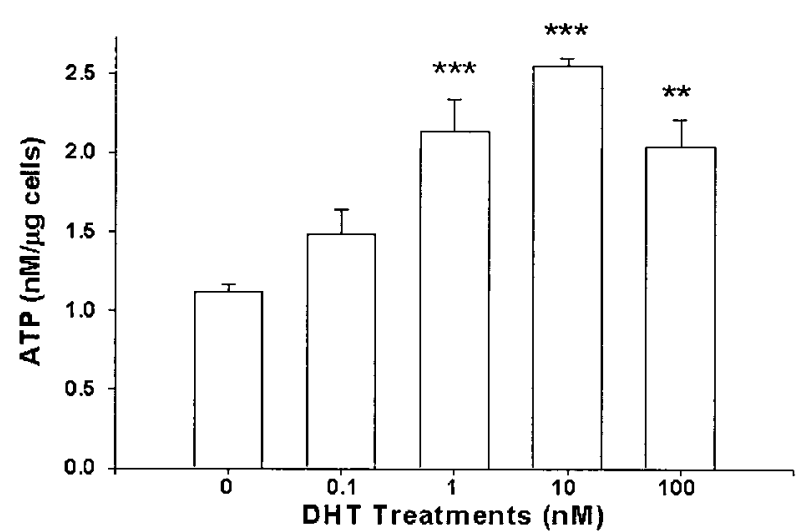

(B)

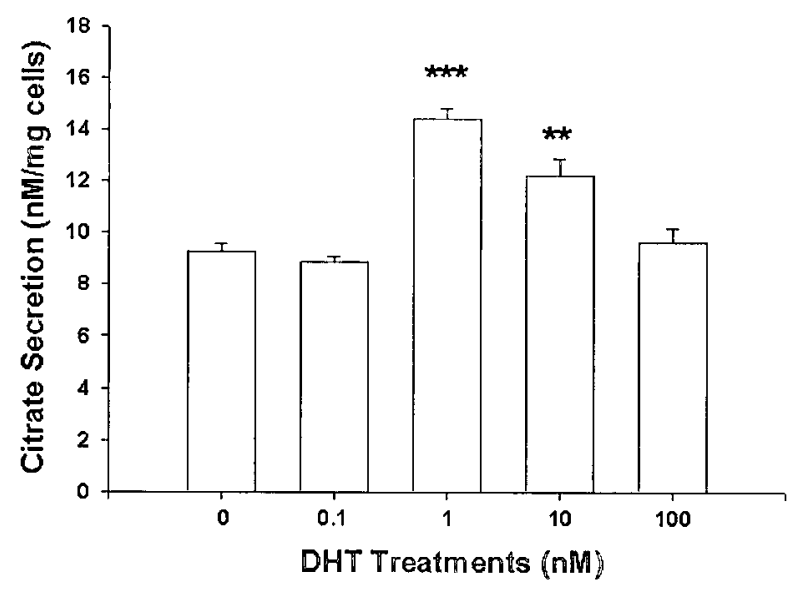

Figure 2 DHT upregulates citrate utility and the bioenergy of LNCaP cells. Cells were treated with different concentrations of DHT $(0 \cdot 1-100 \mathrm{nM})$ in $1 \mathrm{ml}$ RPMI-PRF medium with $2 \%$ CD-FSC for $48 \mathrm{~h}$, cells were harvested to determine intracellular ATP levels (A) and the media were collected for citrate assay (B), as described in Materials and methods. Experimental data are presented as mean \pm S.E. $(n=6)$ of the citrate concentrations and ATP levels induced by DHT treatments, relative to those of the sample that had undergone the control treatment $\left({ }^{\star \star} P<0.05\right.$; $\left.{ }^{* * \star} P<0.001\right)$.

enzymatic activity in the rat ventral prostate but not in the liver or kidneys (Costello et al. 1995). The results obtained herein indicated that DHT induced the enzymatic activity of mACON in LNCaP cells in a manner consistent with an earlier study which suggested that treatment with androgen increases the oxidation of citrate in LNCaP cells (Franklin et al. 1995).
The LNCaP cells express the androgen receptor with a single-base mutation that produces a change from threonine to alanine in the androgen-binding domain. The growth of LNCaP cells is induced by both the agonist and the antagonist of androgen (Kokontis et al. 1991). Most studies agree that PC-3 cells do not express androgen receptor proteins by immumoblotting assay or mRNA, as detected by Northern blotting analysis and S1 nuclease protection assay (Webber et al. 1997). Androgen treatment does not affect the growth of PC-3 cells, even though some studies have stated that PC-3 cells express very low levels of functional androgen receptor (Tilley et al. 1995, Chlenski et al. 2001). However, this study revealed that treatment of androgen receptor-transfected PG-3 cells with DHT reduces the enzymatic activity of mACON. The androgen suppresses the growth of the androgen receptor-transfected PG-3 cells herein in a manner consistent with other in vitro or in vivo studies of the androgen receptor-transfected PC-3 cells conducted in different independent laboratories (Yuan et al. 1993, Umekita et al. 1996, Heisler et al. 1997, Shen et al. 2000, Evangelou et al. 2002, Pizzi et al. 2003).

Immunoblot assay and RT-PCR assay in this study showed that the PCAR9 cells express almost the same concentration of full-length androgen receptor as do the LNCaP cells. The activity of recombinant human androgen in PCAR9 cells appears to be transcriptionally functional by activating the MMTV-CAT reporter gene. Heisler et al. (1997) found that the growth inhibition of androgen receptor-transfected PG-3 cells was inhibited in both the higher and the lower androgen receptor-expressing cell lines and suggested that the observed inhibition of growth is not caused by the overexpression of the androgen receptor. Yuan et al. (1993) indicated that the morphology of androgen receptor-transfected PG-3 cells was distinct from that of cells of the parental cell line. Their studies suggested that DHT treatments block the progression of androgen receptor-transfected $\mathrm{PC}-3$ cells through the cell cycle, resulting in growth inhibition and apoptosis. However, the PGAR9 and PGDNA cells herein did not exhibit significantly different morphologies. DHT treatments were not found to induce apoptosis with DNA fragmentation in the PCAR9 cells (data not shown). All the cells in this study were incubated in the RPMI-PRF medium with 

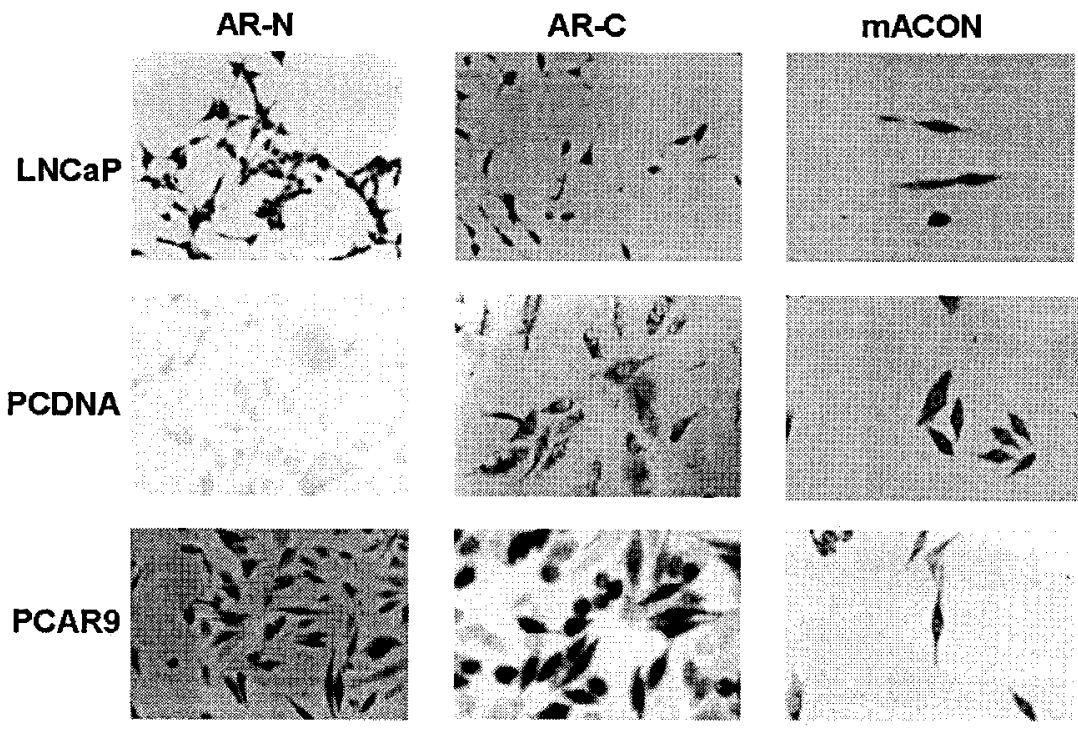

Figure 3 Analysis of the expression of androgen receptor in LNCaP, PCAR9 and PCDNA cells by immunocytochemical staining. LNCaP, PCAR9 and PCDNA cells were immunocytochemically stained with the N-terminal (AR-N) and C-terminal (AR-C) rabbit anti-human androgen receptor polyclone antibodies, and anti-bovine mitochondrial aconitase antiserum (mACON) respectively.

2\% CD-FCS for $48 \mathrm{~h}$ before and after DHT treatment. The low percentage of FCS may have abolished the effect of the cell cycle in this study.

The results obtained herein indicated that DHT inhibits the biosynthesis and the enzymatic activity of mACON, halting the proliferation of androgen receptor-transfected PG-3 cells. Our previous study, using antisense strategy to block the endogenous mACON expression of PG-3 cells, demonstrated the positive correlation among mACON, bioenergy and cell proliferation (Juang 2004a). The androgen receptor-transfected PG-3 cells blocked the mACON enzymatic activity after DHT treatments which was suspected to reduce the cellular bioenergetic synthesis and attenuate cell proliferation.

Results from this study, however, indicated that the medium citrate concentration was decreased after treating PCAR9 cells with DHT. The capability of citrate synthesis and oxidation in prostatic epithelial cells is important in determining the net amount of citrate secretion, and enzymes involved in the metabolism of citrate in the prostate are controlled by each hormone in unison (Costello \& Franklin 2002). Previous study has shown that
DHT modulates not only the oxidation of citrate but also the synthesis of citrate in LNCaP cells (Franklin et al. 1995). It seems that DHT may also modulate some enzymes that are important in metabolizing citrate in PGAR9 cells.

Immunoblot assays and transient gene expression assays indicated that DHT regulates $\mathrm{mACON}$ at the transcriptional level in both $\mathrm{LNCaP}$ and PGAR9 cells although the regulation is in the opposite manner in each type of cell. Results showed that DHT upregulates the reporter activity in both LNCaP and PCAR9 cells when the cells were transfected with the pbGL188 reporter vector. It seems that DHT upregulates the gene expression of mACON via an alternative signaling pathway since simple sequence analysis did not reveal a consensus androgen response element (AGAAGANNNTGTTGT; Nelson et al. 1999) within the DNA fragments. Several studies have revealed that, when the exogenous androgen receptor is stably overexpressed into PG-3 cells, some factors determine whether the transcriptional effect is the ligand-dependent or ligandindependent situation (Gkonons et al. 2000, Evangelou et al. 2002, Pizzi et al. 2003). One study 
(A)

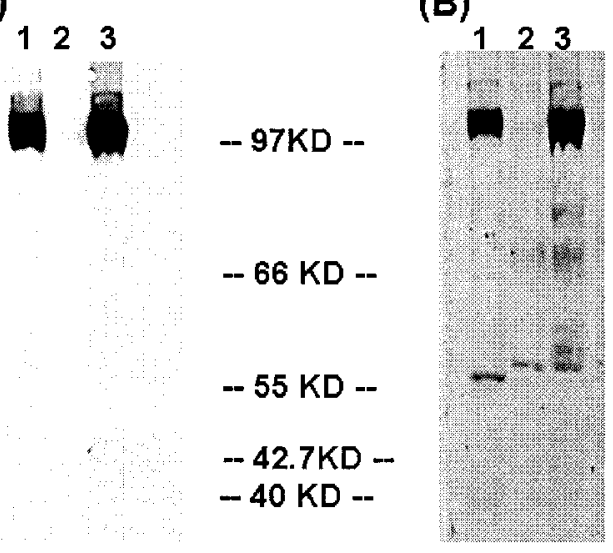

(C) $\quad$-Actin AR1 AR2 AR3

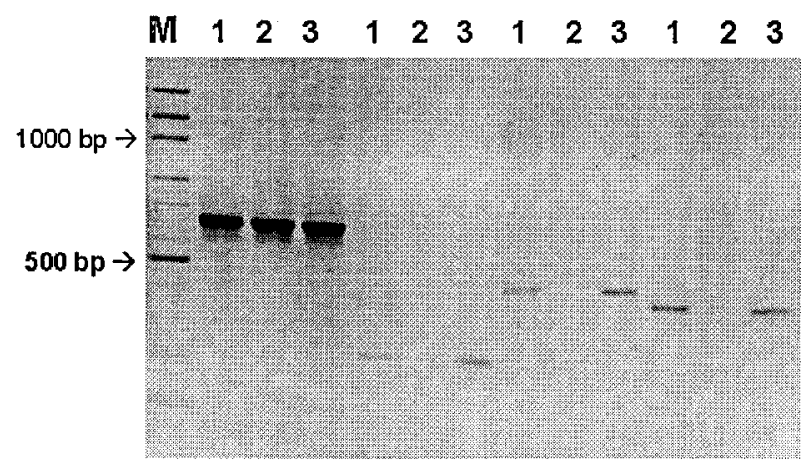

Figure 4 Analysis of the expression of androgen receptor in LNCaP, PCAR9, and PCDNA cells by immunoblotting assay and RT-PCR. The expression of androgen receptor in LNCaP, PCDNA and PCAR9 cells was determined by immunoblotting assay with the $\mathrm{N}$-terminal (A) and C-terminal (B) rabbit anti-human androgen receptor polyclone antibodies. Both LNCaP and PCAR9 cells expressed $110 \mathrm{KDa}$ of the full-size androgen receptor. (C) Total RNAs were isolated from LNCaP, PCAR9 and PCDNA cells and conventional RT-PCR methods were applied to amplify the products specific to androgen receptor and $\beta$-actin. The products were resolved electrophoretically using $2 \%$ agarose gel. Bands were visualized using ethidium bromide staining under u.v. light for photography. The estimated size of AR1, AR2, AR3 and $\beta$-actin from PCR are 309, 457, 406 and 724 bp respectively. M, DNA marker; 1 , LNCaP cells; 2, PCDNA cells; 3, PCAR9 cells.

on the $\alpha$-subunit of the pituitary glycoprotein hormones, luteinizing hormone, have similarly stated that the modulation of transcriptional activity by androgen receptor is independent of direct DNA binding but involves interactions

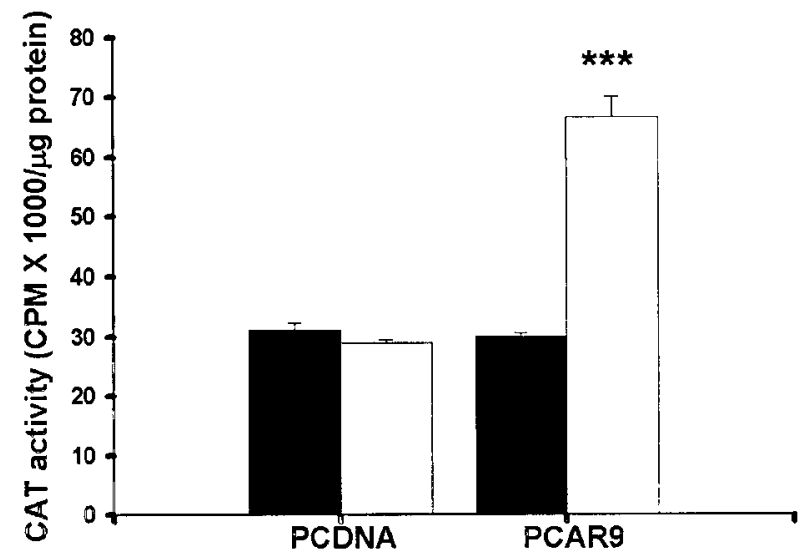

Figure 5 DHT upregulates CAT expression in the stable androgen receptor-transfected PC-3 cell. MMTV-CAT reporter vectors were transiently transfected into PCAR9 and PCDNA cells by lipofectin, as described in Materials and methods. Transfected cells were cultured in RPMI-PRF medium plus $2 \%$ CD-FCS with (open columns) or without (filled columns) $10 \mathrm{nM}$ DHT for an additional $48 \mathrm{~h}$. Experimental data are presented as mean \pm S.E. $(n=5)$ CAT activity induced by treatment with $\mathrm{DHT}$, in relation to that of the sample with the control treatment ( $\left.{ }^{* \star *} P<0.001\right)$.

between the cAMP response element (Heckert et al. 1997). A putative cAMP response element (ACGTCA) has been found within the promoter region of the human mACON gene (Juang 2004b). Another report also indicated that androgen receptor can interact with the RNA polymerase $\mathrm{IIH}$ and the positive elongation factor P-TEFb, which is independent of the androgen response element in androgen receptor-transfected PG-3 cells (Lee et al. 2000).

However, when cells were transiently transfected with the pbGL743 that contained the full-length $(-1013$ to +38$)$ of the 5'-flanking region of the human mACON gene, the promoter activity was enhanced in LNCaP cells but suppressed in PCAR9 cells after treatment with DHT. The divergent regulation of DHT appears to be mediated by the region of 1013-159 bp upstream of the translational starting site of the human mACON gene. Several reports from independent laboratories have indicated that additional coregulators and cis-regulatory elements are important in the regulation of genes by androgen (Lu et al. 2000, Robyr et al. 2000, Haendler et al. 2001). The functions of numerous coregulators of nuclear receptors may be selectively modulated by secondary signal transduction pathways that determined 
(A)

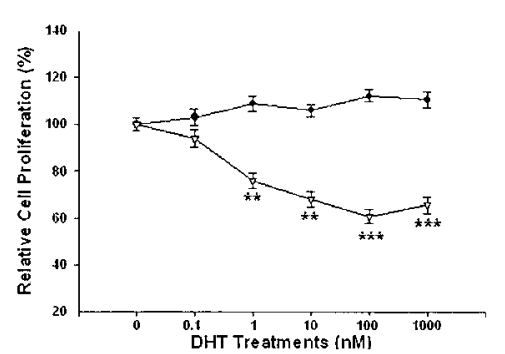

(C)

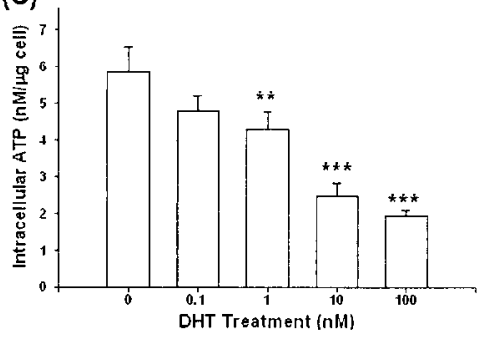

(B)

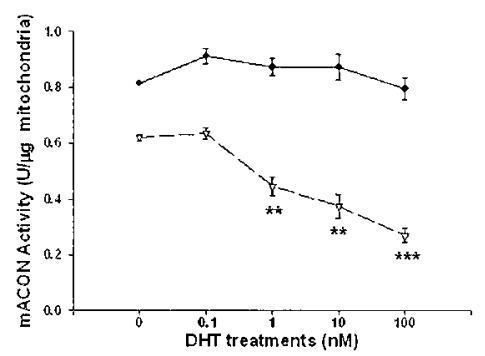

(D)

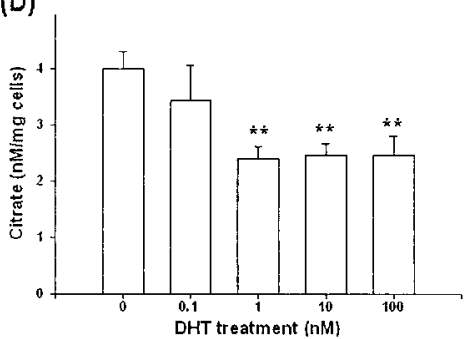

Figure 6 Effect of DHT on cell proliferation, enzymatic activity of mACON, intracellular ATP and citrate secretion of the stable androgen receptor-transfected PC-3 cells. (A) PCAR9 cells $(\nabla)$ and PCDNA cells $(\bullet)$ were incubated with DHT $(0-1000 \mu \mathrm{M})$ in $100 \mu \mathrm{l}$ RPMI-PRF medium with $2 \%$ CD-FCS for 3 days and the cell number was determined by MTS assay. Each point of the curve represents the mean percentage \pm S.E. $(n=8)$ stimulations of $490 \mathrm{~nm}$ absorbance induced by DHT treatments relative to that of a sample that had been mock-treated. (B) PCAR9 cells $(\nabla)$ and PCDNA cells $(\bullet)$ were treated with different concentrations of DHT $(0 \cdot 1-100 \mathrm{nM})$ in RPMI-PRF medium with $2 \% \mathrm{CD}-\mathrm{FCS}$ for $48 \mathrm{~h}$. The mACON enzymatic activities in the mitochondrial fraction were assayed as described in Materials and methods. PCAR9 cells were treated with different concentrations of DHT $(0.1-100 \mathrm{nM})$ in $1 \mathrm{ml}$ RPMI-PRF medium with $2 \%$ CD-FSC for $48 \mathrm{~h}$. Cells were harvested to determine intracellular ATP levels (C) and the media were collected for citrate assay (D). Data from experiments are presented as mean \pm S.E. $(n=6)$ of the intracellular ATP levels and citrate concentration induced by DHT treatments relative to no-treatment controls ( ${ }^{\star \star} P<0 \cdot 05$ ).

whether the modulators act as coactivators or corepressors, although the mechanisms by which the recruitment of corepressors or coactivators regulate the function of the nuclear receptor are still not well understood (Fernandes \& White 2003). Previous study has indicated that the consensus ratio between the coactivator and the androgen receptor determines the regulative function of the androgen receptor in the prostate (McKenna \& O'Mallery 2002). Therefore, DHT may activate the androgen receptor with unidentified coregulatory proteins and then this transcriptional unit binds to the cis-regulatory element, which is presented in the 5 '-flanking region of $\mathrm{mACON}$ gene, thus determining whether the DHT-bound androgen receptor acts as a coactivator or a corepressor in LNCaP and PCAR9 cells. The precise mechanism of the modulation of the transcription of human mACON gene by DHT must be further investigated.

This study successfully cloned cells that express the functional full-length androgen receptor to human androgen-insensitive prostate carcinoma cells, PC-3. The pathways by which the androgen receptor stimulated the growth of $\mathrm{LNCaP}$ cells, but arrested that of PCAR9 cells, are yet to be explained. The paradoxical results concerning mACON gene expression following the treatment 
(A)

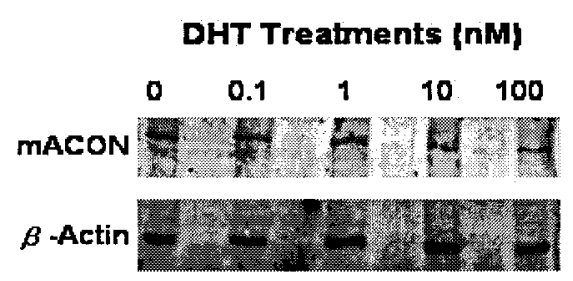

(C)

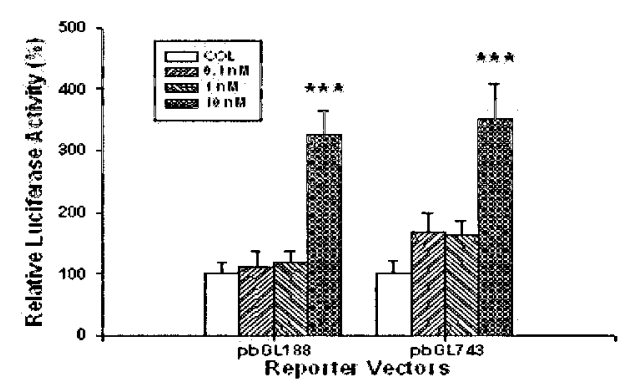

(B)

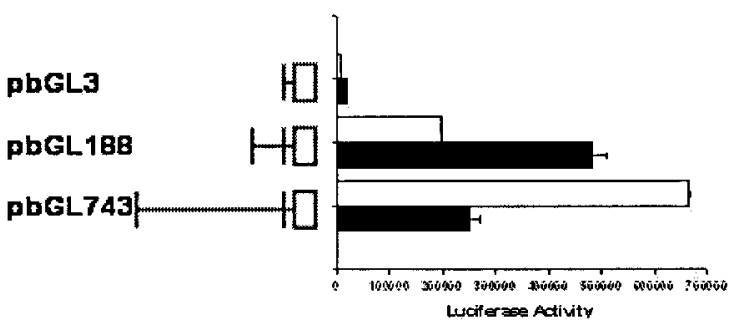

(D)

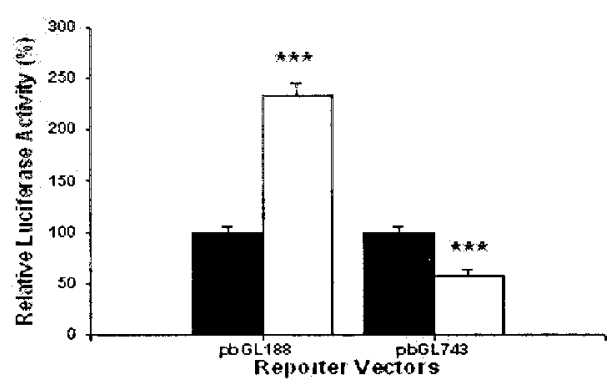

Figure 7 Regulation by DHT of the promoter activity of the mACON gene. (A) PCAR9 cells were treated with different concentrations of DHT. Cells were harvested and lysed to extract protein for immunoblotting assay. (B) Reporter vectors were constructed and transient gene reporter assays carried out as described in Materials and methods. Experimental data were obtained in quadruplicate and are presented as the mean ( \pm S.E.) luciferase activity of reporter vectors (open columns represent LNCaP cells and filled columns represent PCAR9 cells. (C) Regulation by DHT $(0-10 \mathrm{nM})$ of the promoter activity of the mACON gene in LNCaP cells. The columns represent different concentrations of DHT treatments, as stated in the Figure. (D) Regulation by DHT (10 nM) of the promoter activity of the mACON gene in PCAR9 cells. Open columns represent the DHT-treated group and the filled columns represent the control mock-treated group. Experimental data were obtained in quadruplicate and are presented as the mean percentage stimulations ( \pm S.E.) of the luciferase activity induced by DHT treatments, in relation to that associated with the sample that had undergone control mock-treatment.

of LNCaP and PCAR9 cells with DHT, suggested that DHT regulates the expression of the mACON gene expression in a receptor-dependent manner, by modulating unknown non-receptor factors.

\section{Acknowledgements}

We greatly appreciate the generosity of Dr S Liao in providing the human androgen receptor cDNA and that of Dr R B Franklin in providing the mACON antibody.

\section{Funding}

This research was supported by the NHRI (Taiwan, Republic of China) under research grant
HR826, by Chang Gung University research under grants CMRP 937 and D1006, and by the National Science Council (Taiwan) under grant NSC912314-B-182-020.

\section{References}

Chang C, Kokontis J \& Liao S 1988 Structural analysis of complementary DNA and amino acid sequences of human and rat androgen receptors. PNAS 85 7211-7215.

Chlenski A, Nakashiro K, Ketels KV, Korovaitseva GI \& Oyasu R 2001 Androgen receptor expression in androgen-independent prostate cancer cell lines. Prostate 47 66-75.

Costello LC \& Franklin RB 1991 Concepts of citrate production and secretion by prostate: 1 Metabolic relationships. Prostate 18 25-46.

Costello LC \& Franklin RB 1994 The bioenergetic theory of prostate malignancy. Prostate 25 162-166.

Costello LC \& Franklin RB 2002 Testosterone and prolactin regulation of metabolic genes and citrate metabolism of prostate epithelial cells. Hormone and Metabolic Research 34 417-424. 
Costello LC, Liu Y \& Franklin RB 1995 Testosterone stimulates the biosynthesis of $\mathrm{m}$-aconitase and citrate oxidation in prostate epithelial cells. Molecular and Cellular Endocrinology 112 45-51.

Costello LC, Liu Y \& Franklin RB 1996 Testosterone and prolactin stimulation of mitochondrial aconitases in pig prostate epithelial cells. Urology 48 645-649.

Cunha GR, Donjacour AA, Cooke PS, Mee S, Bigsby RM, Higgins SJ \& Sugimura Y 1987 The endocrinology and developmental biology of the prostate. Endocrine Revieres 8 338-362.

Drapier J-G \& Hibbs JB 1996 Aconitase: a class of metalloproteins highly sensitive to nitric oxide synthesis. Methods in Enzymology 269 26-36.

Emptage MH, Kent TA, Kennedy MC, Beinert H \& Munck E 1983 Mossbauer and EPR studies of activated aconitases: development of a localized valence state at a subsite of the $[4 \mathrm{Fe}-4 \mathrm{~S}]$ cluster on binding of citrate. PNAS $\mathbf{8 0} 4674-4678$.

Evangelou A, Letarte M, Marks A \& Brown TJ 2002 Androgen modulation of adhesion and antiadhesion molecules in PC-3 prostate cancer cells expressing androgen receptor. Endocrinology 143 3897-3904.

Fernandes I \& White JH 2003 Agonist-bound nuclear receptor: not just targets of coactivators. Fournal of Molecular Endocrinology 31 1-7

Franklin RB, Khang M, Akuffo V \& Costello LC 1986 The effect of testosterone on citrate synthesis and citrate oxidation and a proposed mechanism for regulation of net citrate production in prostate. Hormone and Metabolic Research 18 177-181.

Franklin RB, Juang HH, Zou J \& Costello LC 1995 Regulation of citrate metabolism by androgen in LNCaP human prostate carcinoma cell line. Endocrine 3 603-607.

Gkonons PJ, Guo F \& Burnstein KL 2000 Type I vasoactive intestinal peptide receptor expression in PC3/AR cells is evidence of prostate epithelial differentiation. Prostate 42 137-144.

Haendler B, Schuttke I \& Schleuning WD 2001 Androgen receptor signaling: comparative analysis of androgen response element and implication of heat-shock protein 90 and 14-13-3 eta. Molecular and Cellular Endocrinology 173 63-73.

Heckert LL, Wilson EM \& Nilson JH 1997 Transcriptional repression of the alpha-subunit gene by androgen receptor occurs independently of DNA binding but requires the DNA-binding and ligand-binding domains of the receptor. Molecular Endocrinolology 11 1497-1506.

Heisler LE, Evangelou A, Lew AM, Trachtenberg J, Elsholtz HP \& Brown TJ 1997 Androgen-dependent cell cycle arrest and apoptotic death in PC-3 prostatic cell cultures expressing a full-length human androgen receptor. Molecular and Cellular Endocrinology 126 59-73.

Horoszeqicz J, Leong S, Kawinski E, Karr J, Rosenthal H, Chu T, Mirand E \& Murphy G 1983 LNCaP model of human prostate carcinoma. Cancer Research 43 1809-1818.

Juang HH $2004 a$ Modulation of mitochondrial aconitase on the bioenergy of human prostate carcinoma cells. Molecular Genetics and Metabolism 81 244-252.

Juang HH 2004b Cyclic adenosine 3',5'- monosphosphate mediate prolactin regulation of mitochondrial aconitase in human prostate carcinoma cells. Molecular and Cellular Endocrinology 219 141-149.

Juang HH, Costello LC \& Franklin RB 1995 Androgen modulation of multiple start sites of the mitochondrial aspartate aminotransferase gene in rat prostate. Fournal of Biological Chemistry $27012629-12634$.

Kaighn ME, Narayan KS, Ohnuki Y, Lechner JF \& Jones LW 1979 Establishment and characterization of a human prostatic carcinoma cell line (PC-3). Investigative Urology 179 16-23.

Kokontis J, Ito K, Hiipakka RA \& Liao S 1991 Expression and function of normal and $\mathrm{LNCaP}$ androgen receptors in androgen-insensitive human prostatic cancer cells. Altered hormone and antihormone specificity in gene transactivation. Reporter 1 271-279.

Lee DK, Duan HO \& Chang C 2000 From androgen receptor to the general transcription factor TFIIH. Identification of $\mathrm{cdk}$ activating kinase (CAK) as an androgen receptor $\mathrm{NH}(2)$-terminal associated coactivator. Fournal of Biological Chemistry 275 9308-9313.

Liao S, Umekita Y, Guo J, Kokontis JM \& Hiipakka RA 1995 Growth inhibition and regression of human prostate and breast tumors in athymic mice by tea epigallocatechin gallate. Cancer Letters 96 239-243.

Lopez-Otin C \& Diamandis EP 1998 Breast and prostate cancer: an analysis of common epidemiological, genetic, and biochemical features. Endocrine Reviews 19 365-396.

Lu S, Jenster G \& Epner DE 2000 Androgen induction of cyclin-dependent kinase inhibitor p21 gene: role of androgen receptor and transcription factor Spl complex. Molecular Endocrinology 14 753-760.

McKenna NJ \& O'Malley BW 2002 Minireview: nuclear receptor coactivatiors - an update. Endocrinology 143 2461-2465.

Möllering H \& Gruber W 1966 Determination of citrate with citrate lyase. Analytical Biochemistry 17 369-376.

Nelson CC, Hendy SC, Shukin RJ, Chen H, Bruchovsky N, Koop BF \& Rennie PS 1999 Determinants of DNA sequence specificity of the androgen, progesterone, and glucocorticoid receptors: evidence for differential steroid receptor response elements. Molecular Endocrinology 13 2090-2107.

Pizzi H, Gladu J, Carpio L, Miao D, Goltzman D \& Rabbani SA 2003 Androgen regulation of parathyroid hormone-related peptide production in human prostate cancer cells. Endocrinology 144 858-867.

Robyr D, Wolffe AP \& Wahli W 2000 Nuclear hormone receptor coregulators in action: diversity for shared tasks. Molecular Endocrinology 14 329-347.

Shen R, Sumitomo M, Dai J, Harris A, Kaminetzky D, Gao M, Burnstein KL \& Nanus DM 2000 Androgen-induced growth of androgen receptor expressing androgen-independent prostate cancer cells is mediated by increased levels of neutral endopeptidase. Endocrinology 141 1699-1704.

Taplin M-E, Bubley GJ, Shuster TD, Frantz ME, Spooner AE, Ogata GK, Keer HN \& Balk SP 1995 Mutation of the androgen-receptor gene in metastatic androgen-independent prostate cancer. New England Fournal of Medicine 332 1393-1398,

Tilley MD, Bentel JM, Aspinall JO, Hall RE \& Horsfall DJ 1995 Evidence for novel mechanism of androgen resistance in the human prostate cancer cell line, PG-3. Steroids 60 180-186.

Umekita Y, Hiipakka RA, Kokontis JM \& Liao S 1996 Human prostate tumor growth in athymic mice: inhibition by androgen and stimulation by finasteride. PNAS 93 11802-11807.

Webber MM, Bello D \& Wuader S 1997 Immortalized and tumorigenic adult human prostatic epithelial cell lines: characteristics and application Part 2. Tumorigenic cell lines. Prostate 30 58-64.

Yuan S, Trachtenberg J, Mills GB, Brown TJ, Xu F \& Keating A 1993 Androgen-induced inhibition of cell proliferation in an androgen-insensitive prostate cancer cell line (PC-3) transfected with a human androgen receptor complementary DNA. Cancer Research 53 1304-1311.

Received in final form 19 March 2004 Accepted 29 March 2004 